\title{
Consumption of Cisatracurium in different age groups, using a closed loop computer controlled system
}

\author{
Shehzaad Joomye ${ }^{1}$, Donglai Yan ${ }^{1}$, Haiyun Wang ${ }^{1}$, Guoqiang Zhou² and Guolin Wang ${ }^{\text {** }}$
}

\begin{abstract}
Background: We devised this study to quantify the effect of age on the consumption of cisatracurium under general anaesthesia, using a computer controlled closed loop infusion system. We further investigated this effect on, sufentanil and propofol consumption.

Methods: 74 patients of physical status I and II, requiring general anaesthesia for elective abdominal surgery, were assigned to three groups. Patients in group 1 were aged from 20 to 45, group 2 were from 46 to 64, and group 3 above 65 years old. General Anesthesia was maintained with propofol and muscle paralysis was maintained using a closed-loop computer controlled infusion of cisatracurium. For analgesia, intermittent bolus of sufentanil $10 \mu \mathrm{g}$ was given.

Results: Cisatracurium consumption in group 1, 2 and 3 were $1.8 \pm 0.3,1.6 \pm 0.4$ and $1.3 \pm 0.4 \mu \mathrm{g} / \mathrm{kg} / \mathrm{min}$ respectively. There was significant difference of cisatracurium consumption between group 1 and $3(P=0.002)$, and the consumption of cisatracurium in group 3 was less as compared with group $2(P=0.04)$. The average recovery index of patients in group 1, 2 and 3 were $8.8 \pm 2.6,11.5 \pm 2.9$ and $12.7 \pm 2.5$ minutes respectively. There were difference between group 1 and $2(P=0.02)$. As compared with group 1 , the recovery index was still longer in group $3(P=0.001)$. Patients in group 1 , 2 and 3 consumed an average sufentanil $0.4 \pm 0.1,0.4 \pm 0.1$ and $0.3 \pm 0.1 \mu \mathrm{g} / \mathrm{kg} / \mathrm{hr}$, respectively. There were statistical significant between group 1 and $3(P<0.0001)$, and the same trend was found between group 2 and $3(P=0.03)$. The Consumption of propofol in group 1,2 and 3 were $5.1 \pm 0.4,4.3 \pm 0.6$ and $3.1 \pm 0.5 \mathrm{mg} / \mathrm{kg} / \mathrm{hr}$. The difference in the propofol consumption was found statistically significant when comparing between any two groups.
\end{abstract}

Conclusion: We concluded that the sensitivity of anesthetic agents increased with age. Less medication was required to achieve a desirable effect in older patients specially those above 65 years of age, and the drug effect was prolonged.

Trial registration: ClinicalTrials.gov Identifier: NCT01785446.

Keywords: Age, Anesthesia, Cisatracurium, Closed-loop computer controlled infusion system, Recovery index, Sufentanil, Propofol

\section{Background}

Aging is a universal and progressive physiologic process characterized by decline end-organ reserve, decrease functional capacity, increasing imbalance of homeostatic mechanisms, and an increasing incidence of pathologic process [1]. With the consideration on the daily increase of surgery on elderly patients, proper adjustment of drug dosage is

\footnotetext{
* Correspondence: wang_guolin@hotmail.com

'Department of Anaesthesiology, Tianjin Medical University General Hospital, Tianjin Research Institute of Anaesthesiology, No. 154 Anshan Road, Heping District, 300052 Tianjin, China

Full list of author information is available at the end of the article
}

required for safe recovery from general anesthesia. To achieve this goal, anesthesiologists should minimize the dosage of anesthetics to avoid the side effect of drug residual, while maintains adequate intra-operative unconsciousness, analgesia and paralysis for older patients. Over-dosage of neuromuscular blocking agents especially in elderly patients can lead to delay in recovery and postoperative residual curarization [2]. Accurate administration of such drugs minimizes such effect. The closed-loop infusion is a very sensitive technique in providing stable surgical operating conditions, while diffusing minimal amount of drug to maintain relaxation at a given level [3].

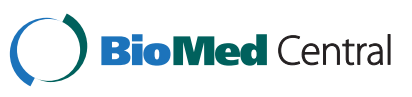


Such technique allowed us not only to calculate accurately its consumption but also to prevent side effects due from over dosage. In this study, we determined the intra-operative consumption of cisatracurium infusion and its recovery index using a closed loop computer controlled system in different aged groups. We also calculated sufentanil and propofol consumption in these groups. The implication of this study may be reassuring to the clinician the effect of age on the profile of muscle relaxant, thus minimize the over dosage and prolonged recovery time.

\section{Methods}

The study was approved by our hospital ethical committee: Board Name; Tianjin Medical University General Hospital Ethics Committee, Board Affiliation; Tianjin Medical University General Hospital Ethics Committee. (Phone: +86-22-60361517). Approval number: 201252.

It was conducted according to the guidelines of the above mentioned ethical requirements, and all patients gave written consent prior the study. Experimental Design and Groups Patients scheduled for elective abdominal general surgery under general anaesthesia were assigned to 3 groups. All patients were of ASA status I and II, and they were all required to give consent before starting the study. Group 1 were aged from 20 to 45 , group 2 from 46 to 64 and group 3 were 65 and above. The exclusion criteria were as follows: patients with neuromuscular junction disorders, myopathies, peripheral neuropathies, encephalopathies, abnormal renal or liver laboratory function test and any patients with flaccid paralysis [4-6] (Additional file 1).

For accurate comparison of drug consumption between groups, all patients must have same induction protocol: midazolam $0.05 \mathrm{mg} / \mathrm{kg}$, sufentanil $0.3 \mu \mathrm{g} / \mathrm{kg}$, etomidate $0.2 \mathrm{mg} / \mathrm{kg}$ and a bolus dose of cisatracurium $0.15 \mathrm{mg} / \mathrm{kg}$ which was given by the computerized closed loop infusion system (CLMSRI-I, Guangxi VERYARK Technology Co., Ltd.). All patients received propofol infusion titrated to the clinical situation in a range of 4.5 to $7.5 \mathrm{mg} / \mathrm{kg} / \mathrm{hr}$ $(75-125 \mu \mathrm{g} / \mathrm{kg} / \mathrm{min})$ according to the BIS value of $40-60$. Hypotension, defined as systolic blood pressure below $80 \mathrm{mmHg}$ or mean arterial pressure below $60 \mathrm{mmHg}$ for more than 5 minutes, was treated by reducing propofol infusion by $0.6 \mathrm{mg} / \mathrm{kg} / \mathrm{hr}(10 \mu \mathrm{g} / \mathrm{kg} / \mathrm{min})$, but within the range of 4.5 to $7.5 \mathrm{mg} / \mathrm{kg} / \mathrm{hr}$. Additional intravenous fluids were given as deemed appropriate. Response was reassessed at 5 minute intervals and the above measures continued until stabilization of blood pressure. Hypertension, defined as systolic blood pressure above $150 \mathrm{mmHg}$ or mean arterial pressure above $95 \mathrm{mmHg}$ for more than 5 minutes, was treated by giving additional sufentanil $(10 \mu \mathrm{g})$ boluses. Sufentanil boluses $(10 \mu \mathrm{g})$ were also given to patients in all groups when there was an increase in the heart rate by more than 20 beats per minute or mean arterial pressure by more than $15 \%$ indicating lightening of anaesthesia. Response was reassessed at 5 minute intervals and the above measures repeated until stabilization.

During the whole procedure of anesthesia, the infusion of cisatracurium and the monitoring of neuromuscular block status were done by the computerized closed loop infusion system (CLMSRI-I, Guangxi VERYARK Technology Co., Ltd.). The degree of neuromuscular blockade was assessed every 20 seconds. Surface electrodes were attached over the ulnar nerve and over the first interosseus muscle and the index finger [7]. The train-of-four (TOF) sequence was used (2 Hz frequency, $100 \mathrm{~ms}$ pulse width), the stimulus output being a rectangular wave with a current of 0-70 mA. The machine calibrated automatically by searching for the optimal signal levels before setting the supramaximal level. Control electromyographic values were obtained after induction and following this, a stable baseline calibration signal was awaited and a second calibration was performed approximately 10 minutes after induction of anesthesia. During this period patients were ventilated manually with a mask. The degree of neuromuscular blockade was defined as the ratio of the measurement of the first twitch in the TOF sequence to the corresponding control value. The desired level of neuromuscular block (i.e., the set point) was set to $90 \%$ (the first twitch (T1) in the TOF sequence $=10 \%$ from control). $\mathrm{Pa}$ tients were intubated when the T1\% dropped below $10 \%$ as compared with baseline value.

After obtaining a stable calibration signal, a bolus dose of cisatracurium $0.15 \mathrm{mg} / \mathrm{kg}$ was administered. We used the ideal body weight (IBW), as defined by Devine's equation, for the calculation of the dose of cisatracurium [8]. Tracheal intubation was performed and the patients were mechanically ventilated using either of the above mentioned gas mixtures. Bolus administration of cisatracurium was followed by infusion of cisatracurium by a modeldriven closed-loop feedback system as described previously [9]. The infusion rate maintained itself at the low rate of $0.2 \mu \mathrm{g} / \mathrm{kg} / \mathrm{min}$ as long as the T1 response was less than $10 \%$, which would automatically increase to $5.0 \mu \mathrm{g} / \mathrm{kg} / \mathrm{min}$ when $\mathrm{T} 1$ is above $10 \%$. The rate of infusion would fall back to $0.20 \mu \mathrm{g} / \mathrm{kg} / \mathrm{min}$ when the $\mathrm{T} 1$ is less than $10 \%$. Once the bolus dose was given after which the infusion rate was set at $0.20 \mu \mathrm{g} / \mathrm{kg} / \mathrm{min}$. Patients were intubated when the T1\% dropped below $10 \%$. The degree of neuromuscular blockage was assessed every 20 seconds throughout the procedure using the TOF testing. The consumption of cisatracurium was recorded in $\mu \mathrm{g} / \mathrm{kg} / \mathrm{hr}$.

Propofol infusion was used in all patients for the maintenance of anesthesia intraoperatively. The rate of infusion was adjusted according to the BIS value (40-60). The total amount of propofol used from induction to skin closure was recorded and its consumption was calculated in $\mathrm{mg} / \mathrm{kg} / \mathrm{hr}$ in each patient. Sufentanil consumption was calculated in 
$\mu \mathrm{g} / \mathrm{kg} / \mathrm{hr}$. The infusion of cisatracurium and propofol were stopped at skin closure. Furthermore, the linear regression analysis was used to establish the relationship between cisatracurium consumption and age.

After which the TOF monitoring was observed, and reversal agents, neostigmine $40 \mu \mathrm{g} / \mathrm{kg}$ with atropine $0.15 \mathrm{mg} / \mathrm{kg}$ [10], were given only when at least two twitches were present according to TOF monitoring. The tracheal extubation was performed after full recovery from neuromuscular block (TOF-ratio $\geq 0.90$ ) [10], the monitoring of airway patency, respiratory rate, continuous oxygen saturation, blood pressure, and pulse were controlled in emergence and recovery. Assessment of the neuromuscular function was based on both physical examination and the TOF monitor. The recovery index (RI), defined as the time required for $\mathrm{T} 1$ of the TOF to recovery from $25 \%$ to $75 \%$ of baseline [11]. Patients would not leave the operating room with the TOF ratio of less than $90 \%$. Fully awake patients, with stable vitals and ability to move all limbs were then transferred to the Post-Anesthetic Care Unit (PACU) for further monitoring. Patients were observed for at least 60 minutes in the PACU before sending back to the ward. Patients should fulfill well defined criteria before being sent back to wards, including [12]: fully conscious oriented in time, space and person; able to maintain a clear airway and exhibit effective protective reflexes; able to lift head and hold up for more than 30 seconds; bilateral firm hand grips and movement of all extremities; clear vision without nystagmus; respiration and oxygenation returned to preoperative base level; stable cardiovascular function on acceptable level with no unexplained irregularity or uncontrolled bleeding; pain and emesis properly controlled and analgesic or antiemetic regime prescribed.

\section{Statistical analysis}

The calculation of the number needed to find a difference of at least $20 \%$ (group 1 or 2 vs group 3; the mean cisatracurium consumption of group 1 and 2 are larger than $1.6 \mu \mathrm{g} / \mathrm{kg} / \mathrm{min}$, and standard deviation $\approx 0.3$ ) with an alpha risk of $5 \%$ and a power (1-beta) of $80 \%$ shows that 20 patients are needed in each group. The SPSS Statistics17.0 software was used for the statistical analysis. All results are given as mean \pm SD. Test of normality was done for each group and one-way ANOVA was used to compare means between the 3 groups followed by Turkey test.

\section{Results}

Table 1 summarizes the demographic data and results of the three groups. There was no significant difference in gender, body mass index and BIS value within the groups.

The average consumption of cisatracurium in group 1 , 2 and 3 were $1.8 \pm 0.3,1.6 \pm 0.4$ and $1.3 \pm 0.4 \mu \mathrm{g} / \mathrm{kg} / \mathrm{min}$ respectively. Figure 1 demonstrates a box plot showing
Table 1 The demographic data and results of the three groups

\begin{tabular}{lccc}
\hline & $\begin{array}{c}\text { Group 1 } \\
\text { (age 20-45) }\end{array}$ & $\begin{array}{c}\text { Group 2 } \\
\text { (age 46-65) }\end{array}$ & $\begin{array}{c}\text { Group 3 } \\
\text { (age >65) }\end{array}$ \\
\hline Number of patients & 21 & 33 & 20 \\
Age & $38.0 \pm 7.0$ & $54.7 \pm 4.5$ & $73.6 \pm 3.2$ \\
Weight & $67.1 \pm 8.6$ & $67.6 \pm 10.5$ & $61.2 \pm 14.4$ \\
BMl & $24.3 \pm 2.16$ & $24.7 \pm 3.2$ & $21.8 \pm 1.8$ \\
Male/Female & $7 / 14$ & $12 / 21$ & $6 / 14$ \\
Cisatracurium consumption, & $1.8 \pm 0.3$ & $1.6 \pm 0.4$ & $1.3 \pm 0.4$ \\
$\mu \mathrm{gg} / \mathrm{kg} /$ min & & & \\
Recovery index, minutes & $8.8 \pm 2.6$ & $11.5 \pm 2.9$ & $12.7 \pm 2.5$ \\
Sufentanil consumption, $\mu \mathrm{gg} / \mathrm{kg} / \mathrm{hr}$ & $0.4 \pm 0.1$ & $0.4 \pm 0.1$ & $0.3 \pm 0.1$ \\
Propofol consumption, $\mathrm{mg} / \mathrm{kg} / \mathrm{hr}$ & $5.1 \pm 0.4$ & $4.3 \pm 0.6$ & $3.1 \pm 0.5$ \\
\hline
\end{tabular}

the decreasing consumption of cisatracurium in the three groups. There was significant difference of cisatracurium consumption between group 1 and $3(P=0.002)$, and the consumption of cisatracurium in group 3 was less as compared with group $2(\mathrm{P}=0.04)$. The increase in the sensitivity of cisatracurium with age was further demonstrated by its increase in recovery index. The average recovery index of patients in group 1, 2 and 3 were $8.8 \pm 2.6,11.5 \pm 2.9$ and $12.7 \pm 2.5$ minutes respectively (Figure 2). There were difference between group 1 and $2(\mathrm{P}=0.02)$. As compared with group 1 , the recovery index was still longer in group $3(\mathrm{P}=0.001)$. We also found a decrease in consumption of sufentanil with age (Figure 3). Patients in group 1, 2 and 3 consumed an average sufentanil $0.4 \pm 0.1,0.4 \pm 0.1$ and $0.3 \pm 0.1 \mu \mathrm{g} / \mathrm{kg} / \mathrm{hr}$, respectively. There were statistical significant between group 1 and $3(\mathrm{P}<0.0001)$, and the same trend was found between group 2 and $3(\mathrm{P}=0.03)$. Figure 4 illustrates the change in propofol consumption. The Consumption of propofol in group 1, 2 and 3 were $5.1 \pm 0.4,4.3 \pm 0.6$ and $3.1 \pm 0.5 \mathrm{mg} / \mathrm{kg} / \mathrm{hr}$. The difference in the propofol consumption was found statistically significant when comparing between any two groups.

To further confirm the relationship between cisatracurium consumption and age, we performed a linear regression analysis. The linear regression model showed an inverse and significant relationship between cisatracurium consumption and age $(\mathrm{p}<0.01)$.

For the unequal number of patients in three groups, we randomly selected 20 patients from group 2 and reanalyzed the statistical results, all these procedures repeated for three times. We still found the same results as compared with the previous one.

\section{Discussion}

This study was designed to better appreciate the impact of age in the consumption of cisatracurium with a closed 


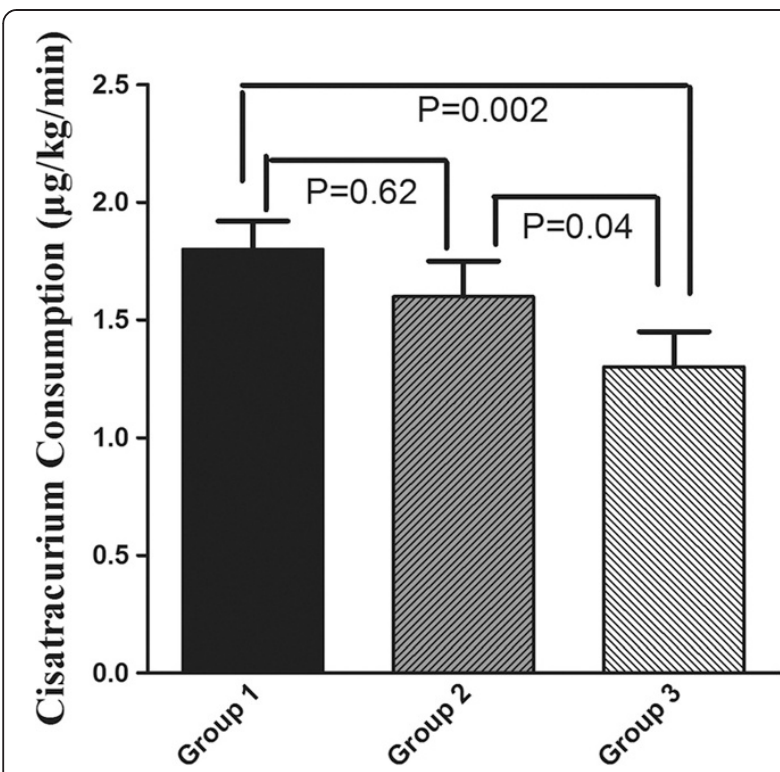

Figure 1 The changes in cisatracurium consumption in the three groups. Group 1: patients aged from 20-45; group 2: aged from 46-65; group 3: aged exceed 65. All results are given as mean $\pm \mathrm{SD}$.

loop computer controlled system. We also studied the effect of age on the recovery index, and the consumption of sufentanil and propofol. We noted a decrease in consumption of cisatracurium with age, and there was a decrease of $26 \%$ in group 3 (older) as compared with group 1 (young patient). A total number of 74 patients were investigated and were divided into 3 groups according to their age. We decided to have more than two groups to better appreciate

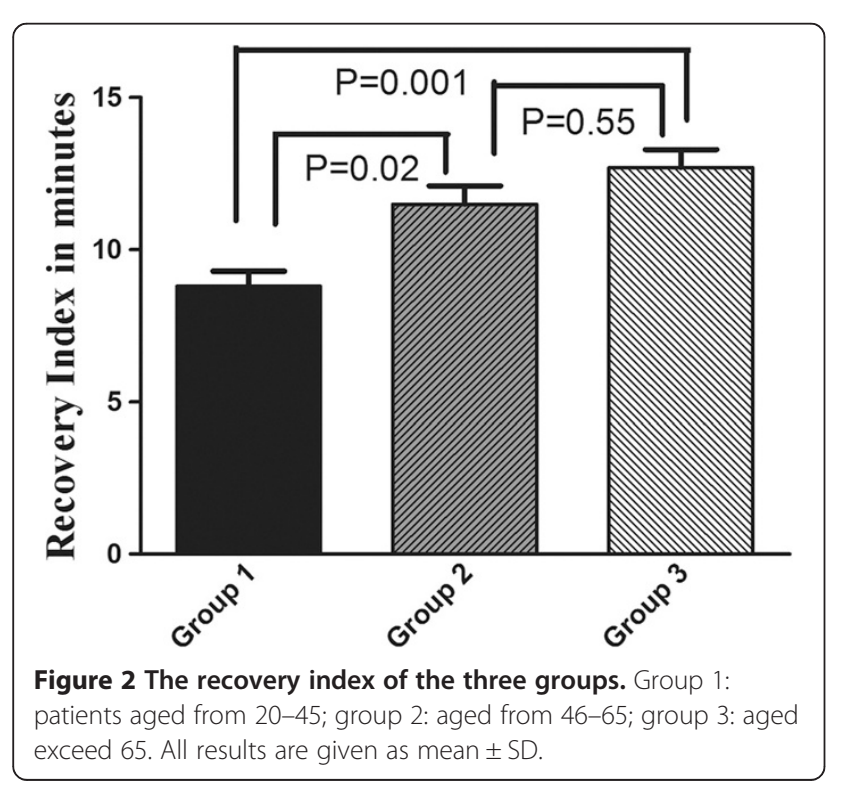

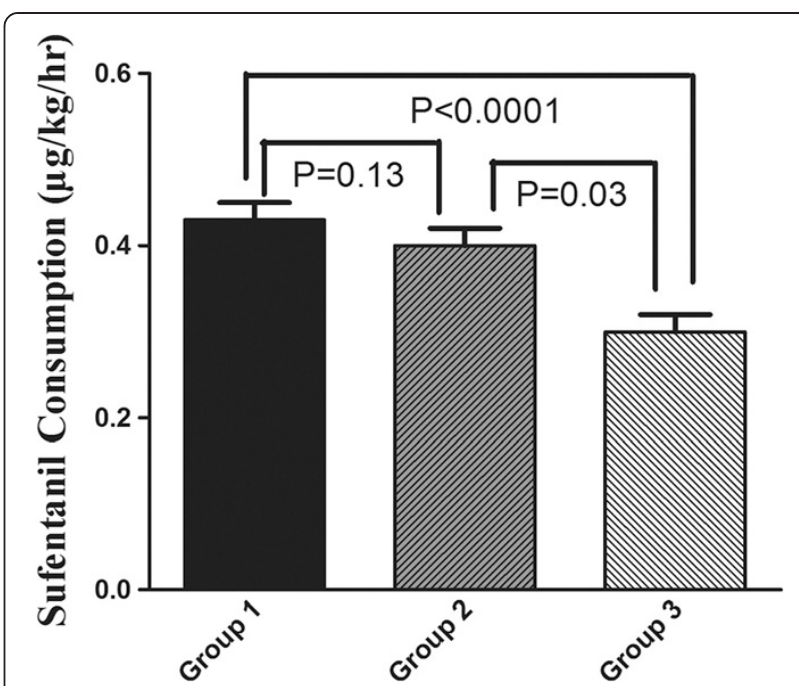

Figure 3 Sufentanil consumption in the three groups. Group 1: patients aged from 20-45; group 2: aged from 46-65; group 3: aged exceed 65 . All results are given as mean \pm SD.

the linear regression of consumption of drugs with age. The pharmacodynamics of muscle relaxants are altered in elderly patients since hepatic metabolism and renal clearance decreases with age. We would expect that the effect of cisatracurium would be unaffected with age since it is eliminated by Hofmann degradation. But our results showed an increase in the effect of cisatracurium with age. Besides the renal and hepatic physiologic changes with age, there are a number of other physiologic changes that accompany the aging process, including decrease in total body water, decrease in lean body mass and muscle mass, increase in

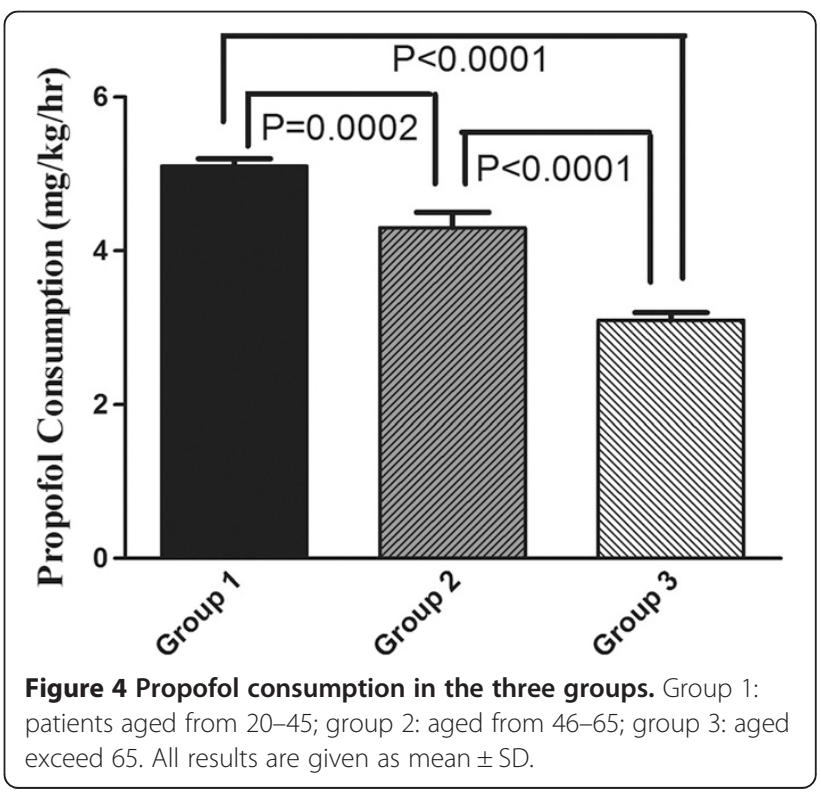


total body fat, decrease in hepatic and renal blood flow, and decrease in cardiac reserve, which account for the altered responses to muscle relaxants $[13,14]$ in aged patients. We might infer that a decrease in total body water could lead to a smaller central compartment and increased serum concentration after bolus dose administration of a drug. In addition the increase in body fat might result in greater volume distribution, with the potential to prolong the clinical effect of a given medication [15]. Furthermore it had been postulated by Cope TM and colleagues that the effect of mivacurium was enhanced in older patients due to a decrease of plasma acetyl cholinesterase activity [16]. Sorooshian SS et al., studies the pharmacodynamics and pharmacokinetics of cisatracurium in young and elderly adults. They found that the plasma clearance of cisatracurium was similar in young and the elderly group, but the volume of distribution was significantly less in the elderly which accounted for delayed response of cisatracurium [17].

Atracurium which also undergoes Hofmann degradation was also found by Kitts and colleagues [18] to have an increasing effect in elderly patients. They concluded that the pharmacokinetics, but not the pharmacodynamics, of atracurium differ significantly between elderly and young adults which resulted in a slightly prolonged effect of neuromuscular blockade in elderly patients. Kisor et al. [19] found that Hofmann clearance accounted for $77 \%$ of total body clearance. Organ clearance was $23 \%$ of total body clearance. Renal clearance, a component of organ clearance, was $16 \%$ of total body clearance, whereas renal clearance of atracurium accounted for $2 \%$ to $10 \%$ of the administered dose, values slightly lower than those found for cisatracurium [20]. Therefore, we think the deteriorating renal function with ages also contributed to the longer effect of cisatracurium in the older age groups. The average age in group 3 is $73.6 \pm 3.2 \mathrm{yr}$, In a review of Cope et al., they stated that the physiological changes such as the decrease in cardiac output and muscle mass, an increase in body fat and the deterioration in renal and hepatic function, which could affect the pharmacokinetics of neuromuscular-blocking agents may not become apparent clinically in healthy individuals until the age of at least 75 years [16]. In our current study, the average age in group 3 is $73.6 \pm 3.2 \mathrm{yr}$, which is close to the age they inferred.

We also demonstrated a decrease in consumption of sufentanil by $32 \%$ in patients above 65 years of age as compared to patients below 45 . Similar results have also been obtained in other studies. Shafer provided a comprehensive review of the pharmacology of sufentanil, alfentanil, and fentanyl in elderly patients [15]. Sufentanil, alfentanil and fentanyl were approximately twice as potent in elderly patients. These findings were primarily related to an increase in drain sensitivity to opioids with age, rather than alterations in pharmacokinetics.

We further investigated the impact of patients' age on propofol consumption. Patients below 45 years of age consumed an average of $5.1 \pm 0.4 \mathrm{mg} / \mathrm{kg} / \mathrm{hr}$ of propofol. Older patients between 46 and 64 consumed $4.3 \pm 0.6 \mathrm{mg} / \mathrm{kg} / \mathrm{hr}$, and elderly patients above 65 consumed $3.1 \pm 0.5 \mathrm{mg} / \mathrm{kg} / \mathrm{hr}$. This showed a decrease of $39 \%$ in consumption between group 1 and 3. For an explanation of the observed results, both pharmacokinetic and pharmacodynamic mechanisms must be considered, i.e. that a defined dose of propofol produces higher drug concentrations in an elderly patient and that the same propofol concentration produces a more profound anaesthetic effect [15]. When comparing the pharmacokinetics of a propofol bolus, Kirkpatrick and colleagues [21] could demonstrate that mean propofol blood concentrations tended to be higher in elderly (65$80 \mathrm{yr})$ than in younger (18-35 yr) patients, best explained by a significantly lower metabolic propofol clearance and a smaller volume of the central compartment. Furthermore, Schüttler and Ihmsen found a linear decrease of the propofol elimination clearance in patients older than $60 \mathrm{yr}$ [22]. These findings may be explained by a reduction of liver function or liver blood flow in elderly patients [23], as the propofol clearance has been characterized as liver blood flow dependent [24]. For propofol pharmacodynamics, agerelated changes of brain function must be considered. Comparing a 20- and a 90-yr-old individual, brain undergoes an age-dependent weight reduction of approximately $10 \%$, while the gray matter decreases more than the white matter [25]. Concomitantly, the cell number of the frontal cortex decreases by approximately $40 \%$ [26]. Our clinically obtained data are supported by results of Schnider and colleagues [27] who, in a laboratory setting, reported that elderly patients were more sensitive to hypnotic and EEG effects of propofol than were younger persons.

\section{Conclusions}

In conclusion, we summarized that the sensitivity of cisatracurium increases with age of patients. Less cisatracurium was required to achieve a desirable effect in elder population with a closed loop infusion system. Even though the dose decreases in the elder patients, a prolonged duration of action of cisatracurium was observed among patients above 65 years of age. We also found that the consumption of propofol and sufentanil decrease in elderly as compared with young adult and middle adult population. These implied for the clinicians that older patients would need a downward adjustment in medication dose during general anesthesia.

\section{Additional file}

Additional file 1: CONSORT 2010 Flow Diagram. 


\section{Competing interests}

The authors declare that they have no competing interests.

\section{Authors' contributions}

SJ helped design the study, conduct the study, analyze the data, and write an initial draft of manuscript. DY recruited the patients, performed many of measurements, data analysis, and manuscript revisions. HW contributed to study design, patient recruitment, data analysis, and manuscript preparation. GZ contributed to patient recruitment, data collection and analysis, and manuscript preparation. GWdesigned the study, collected and analyzed the data, and revised the manuscript. All authors read and approved the final manuscript.

\section{Authors' information}

Donglai Yan is co-first author.

\section{Acknowledgements}

Our gratitude goes to all the staff of the Anaesthesiology Department of Tianjin Medical University General Hospital. Special thanks to Dr Wang Zhuang and Dr Wang Shu who have put trust in our work and allowing us to recruit their patients for the study. Also we would like to thank the members of the statistical department specially Prof Niu Kaijun who have been of great help for us in the statistical work

Financial support and sponsorship: This study was supported by Natural Science Foundation of China $(81371245,81071059,81100984$, 30972847), Science and Technology Supported Key Project of Tianjin (12ZCZDSY03000), Scientific Grant from Tianjin Health Bureau (09KZ106).

\section{Author details}

'Department of Anaesthesiology, Tianjin Medical University General Hospital, Tianjin Research Institute of Anaesthesiology, No. 154 Anshan Road, Heping District, 300052 Tianjin, China. ${ }^{2}$ Department of Anaesthesiology, Tianjin Second People's Hospital, NO.7 South Road, Nankai District, 300192 Tianjin, China.

Received: 17 April 2013 Accepted: 9 April 2014

Published: 21 April 2014

\section{References}

1. Weinert BT, Timiras PS: Invited review: Theories of aging. J Appl Physiol (1985) 2003, 95(4):1706-1716.

2. Butterly A, Bittner EA, George E, Sandberg WS, Eikermann M, Schmidt U: Postoperative residual curarization from intermediate-acting neuromuscular blocking agents delays recovery room discharge. Br J Anaesth 2010, 105(3):304-309.

3. Mason DG, Linkens DA, Edwards ND, Reilly CS: Development of a portable closed-loop atracurium infusion system: systems methodology and safety issues. Int I Clin Monit Comput 1996, 13(4):243-252.

4. Jones DR, Lee HT: Perioperative renal protection. Best Pract Res Clin Anaesthesiol 2008, 22(1):193-208.

5. Child CG, Turcotte JG: Surgery and portal hypertension. Major Probl Clin Surg 1964, 1:1-85.

6. Pugh RN, Murray-Lyon IM, Dawson JL, Pietroni MC, Williams R: Transection of the oesophagus for bleeding oesophageal varices. Br J Surg 1973, 60:646-649.

7. Fuchs-Buder T, Claudius C, Skovgaard LT, Mirakhur RK, Viby-Mogensen J: Good clinical research practice in pharmacodynamic studies of neuromuscular blocking agents II: the Stockholm revision. Acta Anaesthesiol Scand 2007, 51:789-808.

8. Devine BJ: Gentamicin therapy. Drug Intell Clin Pharm 1974, 8:650-655.

9. Olkkola KT, Schwilden H: Quantitation of the interaction between atracurium and succinylcholine using closed-loop feedback control of infusion of atracurium. Anesthesiology 1990, 73:614-618.

10. Adamus M, Belohlavek R, Koutna J, Vujcikova M, Janaskova E: Cisatracurium vs. Rocuronium: a prospective, comparative, randomized study in adult patients under total intravenous anaesthesia. Biomed Pap Med Fac Univ Palacky Olomouc Czech Repu 2006, 150(2):333-338.

11. Jellish WS, Brody M, Sawicki K, Slogoff S: Recovery from neuromuscular blockade after either bolus and prolonged infusions of cisatracurium or rocuronium using either isoflurane or propofol-based anesthetics. Anesth Analg 2000, 91(5):1250-1255.
12. Vimlati L, Gilsanz F, Goldik Z: Quality and safety guidelines of postanaesthesia care: Working Party on Post Anaesthesia Care (approved by the European Board and Section of Anaesthesiology, Union Europeenne des Medecins Specialistes). Eur J Anaesthesiol 2009 26(9):715-721.

13. Sadean MR, Glass PS: Pharmacokinetics in the elderly. Best Pract Res Clin Anaesthesiol 2003, 17(2):191-205.

14. Vuyk J: Pharmacodynamics in the elderly. Best Pract Res Clin Anaesthesiol 2003, 17(2):207-218.

15. Shafer SL: The pharmacology of anesthetic drugs in elderly patients. Anesthesio/ Clin North America 2000, 18(1):1-29. v.

16. Cope TM, Hunter JM: Selecting neuromuscular-blocking drugs for elderly patients. Drugs Aging 2003, 20(2):125-140.

17. Sorooshian SS, Stafford MA, Eastwood NB, Boyd AH, Hull CJ, Wright PM: Pharmacokinetics and pharmacodynamics of cisatracurium in young and elderly adult patients. Anesthesiology 1996, 84(5):1083-1091.

18. Kitts JB, Fisher DM, Canfell PC, Spellman MJ, Caldwell JE, Heier T, Fahey MR, Miller RD: Pharmacokinetics and pharmacodynamics of atracurium in the elderly. Anesthesiology 1990, 72(2):272-275.

19. Kisor DF, Schmith VD, Wargin WA, Lien CA, Ornstein E, Cook DR: Importance of the organ-independent elimination of cisatracurium. Anesth Analg 1996, 83(5):1065-1071.

20. Ward S, Boheimer N, Weatherley BC, Simmonds RJ, Dopson TA: Pharmacokinetics of atracurium and its metabolites in patients with normal renal function, and in patients in renal failure. $\mathrm{Br} J$ Anaesth 1987, 59(6):697-706.

21. Kirkpatrick T, Cockshott ID, Douglas EJ, Nimmo WS: Pharmacokinetics of propofol (diprivan) in elderly patients. Br J Anaesth 1988, 60(2):146-150.

22. Schuttler J, Ihmsen H: Population pharmacokinetics of propofol: a multicenter study. Anesthesiology 2000, 92(3):727-738.

23. Wynne HA, Cope LH, Mutch E, Rawlins MD, Woodhouse KW, James OF: The effect of age upon liver volume and apparent liver blood flow in healthy man. Hepatology 1989, 9(2):297-301.

24. Schnider TW, Minto CF, Gambus PL, Andresen C, Goodale DB, Shafer SL, Youngs EJ: The influence of method of administration and covariates on the pharmacokinetics of propofol in adult volunteers. Anesthesiology 1998, 88(5):1170-1182

25. Brody H: The aging brain. Acta Neurol Scand Supp/ 1992, 137:40-44.

26. Brody H: Structural Changes in the Aging Nervous System. In Interdisciplinary Topics in Gerontology. Edited by Blumenthal HT. Basel: Karger; 1970:9-21.

27. Schnider TW, Minto CF, Shafer SL, Gambus PL, Andresen C, Goodale DB, Youngs EJ: The influence of age on propofol pharmacodynamics. Anesthesiology 1999 90(6):1502-1516.

doi:10.1186/1471-2253-14-29

Cite this article as: Joomye et al.: Consumption of Cisatracurium in different age groups, using a closed loop computer controlled system. BMC Anesthesiology 2014 14:29.

\section{Submit your next manuscript to BioMed Central and take full advantage of:}

- Convenient online submission

- Thorough peer review

- No space constraints or color figure charges

- Immediate publication on acceptance

- Inclusion in PubMed, CAS, Scopus and Google Scholar

- Research which is freely available for redistribution 